\title{
A Validated Modelling Technique for Incorporating Residual Stresses in Glass Structural Design
}

\author{
Mithila Achintha \\ School of Engineering, University of Southampton, Southampton, SO17 1BJ, UK \\ E-mail: Mithila.Achintha@soton.ac.uk
}

\begin{abstract}
This paper presents the development of a simple parabolic residual stress depth profile model for characterising residual stresses in construction-sector glass. The proposed model requires only the knowledge of the surface residual stress, which is usually available from glass manufacturers. Unlike the complex computational techniques reported in the literature, such as modelling physical, microstructural and mechanical phenomena of glass at different temperatures during manufacturing, the proposed model obviates the need for modelling multi-physics phenomenon of the generation of residual stresses. The proposed model also eliminates the need of sophisticated experimental equipment, such as Scattered-LightPolariscopes (SCALP), which are usually not available among practicing engineers, in order to characterise the residual stresses. Residual stress predictions from the proposed parabolic model were validated against experimental results reported in the literature. Using the concept of eigenstrains, the paper also extends the results of the proposed parabolic residual stress depth profile model for incorporating the effects of residual stresses in stress analysis of glass structures.
\end{abstract}

\section{Keywords:}

Construction-sector glass, Eigenstrains, Parabolic, Residual stress, Stress analysis, Structures 


\section{Introduction}

Transparency, aesthetics characteristics, durability and low cost of construction-sector glass (also known as float glass / flat glass / architectural glass) means glass is increasingly used in modern buildings. Appropriate use of glass in buildings has potential for significantly reducing the reliance on artificial lighting. Furthermore, solar energy gained through glass may be harvested for space and water heating. Recent advances in glass products/technologies, such as glass with low-emissivity, solar control, self-cleaning, etc. further enhance the potential use of glass as a means of ensuring energy efficiency in buildings. However, despite the increasing interest in the construction industry, design and construction of glass structures beyond conventional simple structures pose challenges to structural engineers. This is because glass is brittle and its tensile strength is low compared to other construction materials such as steel. Structural behaviour of glass is significantly different to that of widely used nonbrittle construction materials, reinforced concrete, steel and timber.

The brittle material behaviour and the low tensile strength of glass means that accurate stress analysis of glass structures is required in order to ensure safety and structural efficiency. One of the major limitations that hampers performing accurate stress analysis of glass structures is the unavailability of a method for incorporating the effects of residual stresses in construction-sector glass. Residual stresses are developed in glass owing to the differential cooling experiences during the manufacturing processes. Flat glass is manufactured by using the float process where the ingredients are first heated in a furnace to $\sim 1600^{\circ} \mathrm{C}$ and followed by slow cooling to form flat glass sheets [1]. The basic flat (float) glass (also known as annealed glass) can be further thermally-strengthened by heating up to temperatures of $\sim 620^{\circ} \mathrm{C}$ and then rapidly cooling by jets of air (i.e. quenching) [2]. When molten glass cools during manufacturing of annealed glass, and during additional thermal treatments of thermallystrengthened glass, the surface regions solidify first and the subsequent cooling of inner core generates tensile stresses in mid-thickness regions of glass. The mid-thickness tensile 
residual stresses are then balanced by compressive residual stresses developed in the surface regions [2].

The magnitude of the residual stresses in float glass depends on the rate of cooling of hot glass. In annealed glass where glass cooled gradually at a slower rate, low magnitudes of residual stresses (usually less than $<10 \mathrm{MPa}$ ) are present [3]. However, rapid cooling purposely used to strengthen annealed glass cause relatively high magnitudes of residual stresses in thermally-strengthened glass [4]. In construction industry, glass with surface compressive residual stress of magnitude $\sim 25-50 \mathrm{MPa}$ are classified as partially-strengthened or heat-strengthened glass [5]. Fully-strengthened glass, which are commonly known as tempered glass or toughened glass, has surface compressive residual stress of magnitude 80-150 MPa [5]. Cracks/flaws usually initiate in the surface regions of glass and the propagation of these cracks cause glass fracture. Presence of a surface compressive residual stress causes a higher apparent tensile strength in thermally-strengthened glass compared to that in annealed glass [2]. Residual stresses also govern the fracture behaviour. Annealed glass fractures into large shards of angular shapes, whereas tempered glass shatters into small rounded dices of few millimetres (see Figure 1). This is because high magnitudes of surface compressive stresses in the surface regions of glass are associated with high midthickness tensile stresses, and hence, penetration of cracks beyond the surface compressive residual stress layer cause rapid fracture in tempered glass [2]. Thus, glass with high surface residual stress, such as tempered glass, are strong, but they are brittle with no post-fracture load resistance [5]. 
(a)

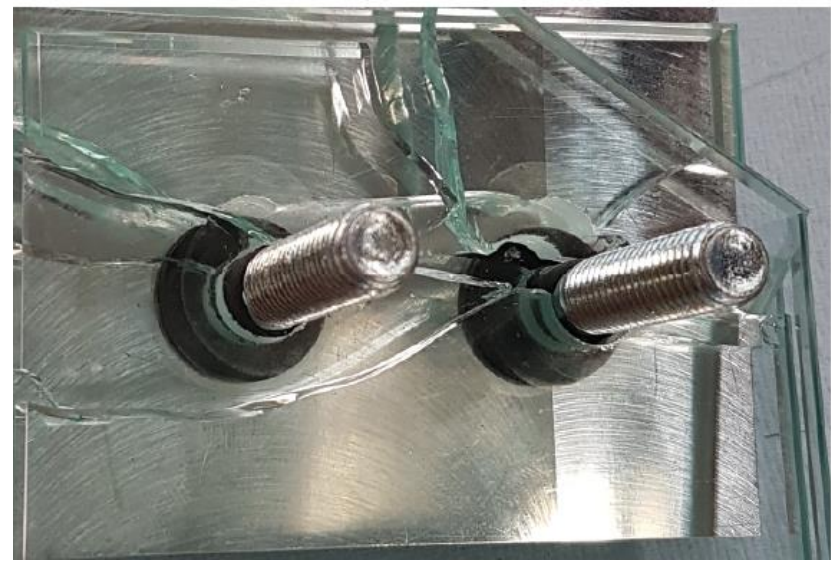

(b)

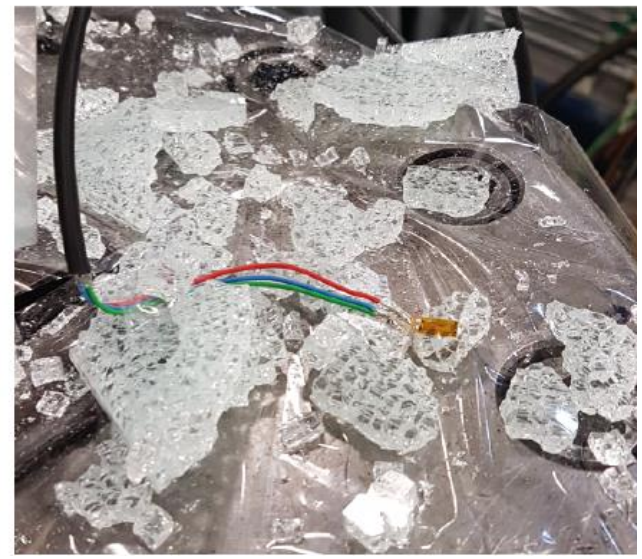

Figure1: Glass fracture pattern: (a) annealed glass and (b) tempered glass

Effects of residual stresses are critical for performance of glass structures. For example, unexpected failure can occur because residual stresses have critically combined with the stresses developed due to the loads applied on the structures. Effects of the residual stresses are more prominent in glass compared to that in other materials such as metal alloys, because of the relatively low tensile strength and the brittle material behaviour of glass.

Despite the possible critical significance of the effects of residual stresses, the current industrial design guidelines of glass structures do not explicitly incorporate the effects of residual stresses. For example, residual stresses in annealed glass are ignored. In the case of thermally-strengthened glass, the current industry practice is to first carry out the stress analysis without including the effects of residual stresses and then ensuring the maximum design surface tensile stress is less than the actual surface compressive residual stress. However, the effects of residual stresses in glass structures depend on actual throughthickness residual stress distribution, and hence, designing structures based on the knowledge of the surface residual stress and the design surface stress alone is not accurate. For example, experimental results (e.g. [6]) showed the influence of the thickness of glass where the fragmentation behaviour of glass of different thicknesses was not explained by the knowledge of surface residual stress [6]. The current practice of not explicitly considering the 
effects of residual stresses mean that glass structures are typically overdesigned with high safety factors, leading to excessive material usage as well as added weight and cost.

\subsection{Experimental characterisation of residual stresses in construction-sector glass}

Despite the advances in the use of experimental techniques such as X-ray/neutron diffraction methods for investigating residual stresses in metal alloys (e.g. [7]), the methods are not commonly used for characterising residual stresses in glass. However, although direct experimental results for stress data during the annealing/tempering processes are not reported in the literature, reliable experimental results are available for the stabilised residual stress states in fully-solidified construction-sector glass. For example, optics-based techniques provide useful tools for measuring stresses in glass, in particular, stresses in the surface regions of glass sheets. Conventional optics methods include the use of photoelasticity [8], whereas methods based on scattered light are becoming more popular (e.g. $[9,10])$ as a reliable technique. It is believed that recently developed scattered light polariscopes (SCALP) $[10,11]$, which determine stresses in glass based on measurement of polarisation of an input laser beam, can be used to measure residual stresses in glass up to about a few millimetres deep from the surface. However, reliable SCALPs are not widely available among the engineers, and even using one only the residual stresses in the surface regions of glass sheets can be measured. Therefore, there is a need for a more practically feasible method not only to know the full through-thickness residual stress depth profiles in glass, but to incorporate the effects of residual stresses in structural design of glass structures.

\subsection{Numerical modelling of residual stresses in construction-sector glass}

Generation of residual stresses in glass involves a complex multi-physics phenomenon. Therefore, development of a method for modelling residual stresses in glass is challenging. The early works of Narayanaswamy [3, 4] proposed modelling structural relaxation owing to differential cooling of hot glass as a means of characterising residual stresses in glass. In recent years, using Finite Element (FE)-based computer packages, advanced numerical 
models for material behaviour of glass under representative temperature history were used for modelling residual stresses in glass [12,13]. Generally, a knowledge of thermal parameters and the viscous response of glass at different temperatures will be required in the analysis reported in the literature. However, these parameters are difficult to determine as they depend on complex thermal phenomena like convection and radiation and microstructural rearrangement of the material. A detailed review of modelling techniques of the generation of residual stresses in glass can be found elsewhere (e.g. [12]) and is not repeated here. The models and the research reported in the literature provide some useful insight into the residual stresses present in construction-sector glass. However, the difficulty of knowing the relevant thermal, material and mechanical parameters and the computational complexity of the analyses means that the methods are too complex and impractical to be used in stress analysis for structural design of real-life glass structures.

In the first half of this paper, a simple parabolic shape residual stress depth profile model is developed for construction-sector glass. This model requires only the knowledge of surface residual stress. The predictions from the proposed parabolic model were validated against the measured residual stress depth profiles reported in the literature for both annealed and thermally-strengthened glass test specimens. In the latter half of the paper, knowledge of the proposed parabolic residual stress depth profile is extended to develop an eigenstrains-based modelling technique for accurately incorporating the effects of residual stress in stress analysis of glass structures.

\section{Residual stress depth profile in construction-sector glass}

It is widely believed that the residual stresses generated due to uniform symmetric cooling of molten glass is symmetric and parabolic relative to the median plane of the glass sheet $[14,15]$. It is also reasonable to assume that the residual stress state in glass, far away from edges of the panels, is a homogeneous planar hydrostatic stress - i.e. normal stresses acting on any 
plane are equal with negligible shear and through-thickness stresses in the material $[13,15]$. Although direct experimental results for stress data during the annealing/tempering processes are not reported in the literature, reliable experimental results are available for stabilised residual stress states in fully-solidified flat glass. For example, results obtained from SCALPS suggest a parabolic shape of the residual depth profile in annealed and thermallystrengthened glass (e.g. $[6,9,10,16])$.

Figure 2 shows the typical residual depth profile in construction-sector glass sheets. Owing to the homogeneous planar hydrostatic state of residual stress, the knowledge of only one principal stress component is sufficient to represent the residual stress state in a given glass sheet. Analytical and computational models, which considered temperature dependent viscosity and structural relaxation of glass during annealing/tempering (e.g. [12, 13, 17]), predicted parabolic residual stress depth profiles similar to the ones determined experimentally. Various closed-formed parabolic residual stress depth profiles were assumed in the literature where most models considered the thickness of the compression zone (i.e. $h_{c}$ in Figure 2) at either side is $20 \%$ of the overall thickness of the glass (e.g. [13]). However, existing models never used the knowledge of the actual residual stress values and the static equilibrium of the residual stress distribution as means of determining the residual stress depth profiles. Due to this limitation the models reported in the literature often do not satisfy equilibrium and compatibility requirements. By using the knowledge of parabolic shape of the residual stress depth profile together with the actual stress at the surface, a model for residual stress depth profiles in construction-sector glass is developed below. 


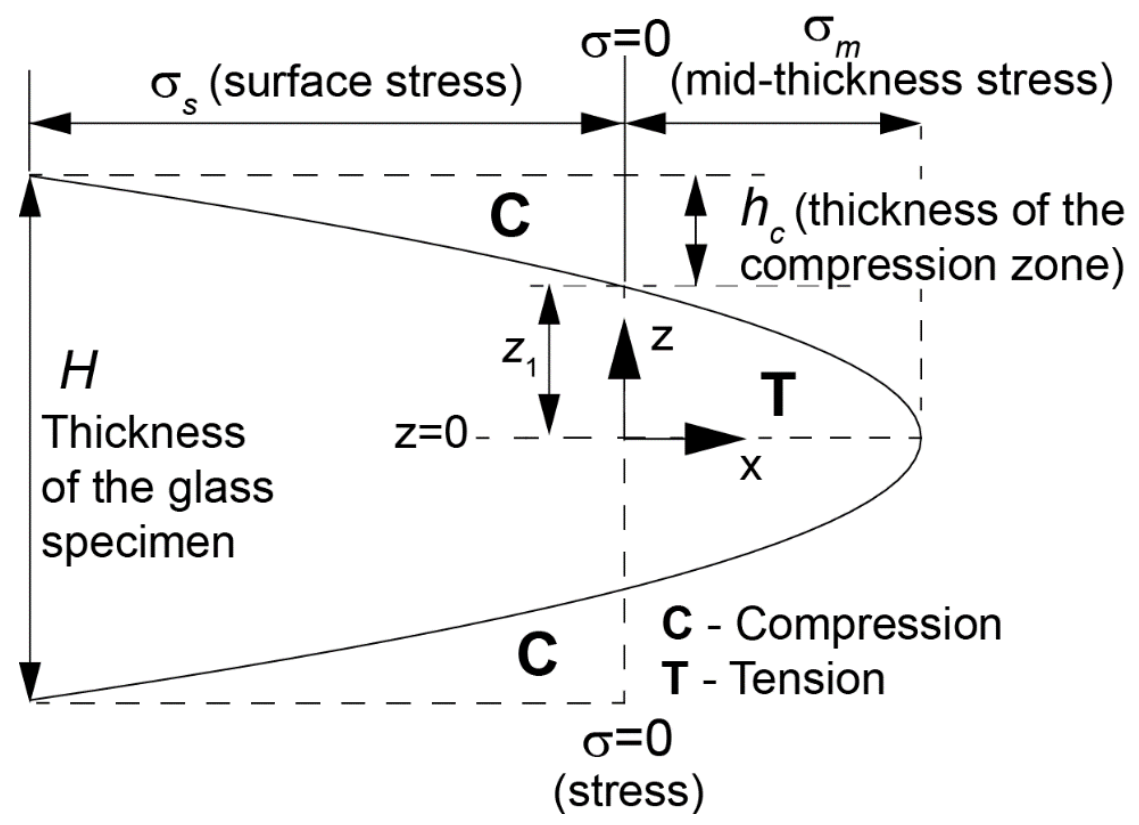

Figure 2: Residual stress depth profile in construction-sector glass

\section{Proposed parabolic model for residual stress depth profile}

Since the residual stress depth profile is symmetric relative to the mid-plane of a glass specimen, it is possible to represent it as a parabola with axis of symmetry parallel to the $x$ axis (see Figure 2). The equation of this type of parabola on $x$ - $z$ plane ( $x$-axis - residual stress and $z$-axis - thickness of the glass specimen) can be represented as $x=a(z-k)^{2}+p$, where $a$ is a coefficient and $p$ and $k$ represent the distances that the parabola has been translated along the $x$ and $z$ axes, respectively [18].

Since the residual stress depth profile is symmetric relative to the mid-plane, $k=0$ and $p$ equals to the residual stress at mid-thickness $\left(\sigma_{m}\right)$ (i.e. $p=\sigma_{m}$ ) (see Figure 2). Thus, the residual stress depth profile can be expressed as $\sigma_{R S}(z)=a z^{2}+\sigma_{m}$, where $\sigma_{R S}(z)$ is the residual stress at distance $z$ from the mid-plane. The knowledge of the known surface residual stress $\left(\sigma_{s}\right)$ and the through-thickness static equilibrium can be used to determine the two unknown parameters, $a$ and $\sigma_{m}$. 
Let, the known surface stress, which is usually available from the glass manufacturer, is $\sigma_{s}$. Thus, $\sigma_{R S}\left(z=h_{l}\right)=\sigma_{s}$, where $h_{1}=H / 2(H$ - thickness of the glass specimen):

$$
\sigma_{s}=a h_{1}^{2}+\sigma_{m}
$$

Static equilibrium, symmetric characteristics of the residual stress depth profile about the midthickness plane and the uniform spatial distribution of residual stress distribution in $x-y$ plane means that the total force due to the residual stresses acting on top-half of the specimen over an unit area on $x-y$ plane is zero - i.e. $\int_{0}^{h 1} \sigma_{R S}(z) d z=0$ :

Thus,

$$
\int_{0}^{h 1} \sigma_{R S}(z) d z=\int_{0}^{h 1}\left(a z^{2}+\sigma_{m}\right) d z=0
$$

Solution of Eqs. 1 and 2 (see Appendix A for the detailed solution) gives:

$$
\begin{aligned}
& \sigma_{m}=-\frac{\sigma_{s}}{2} \\
& a=\frac{6 \sigma_{s}}{H^{2}}
\end{aligned}
$$

Thus, the residual stress depth profile can be uniquely defined as:

$$
\sigma_{R S}(z)=\frac{6 \sigma_{S}}{H^{2}} z^{2}-\frac{\sigma_{S}}{2}
$$

\subsection{Depth of the surface compression zone}

The location at which the residual stress is zero (i.e. $z_{1}$ in Figure 2) can be determined by using the knowledge of the residual stress depth profile (i.e. Eq. (5)).

$$
\begin{aligned}
& \text { At } z=z_{1}, \sigma_{R S}(z)=0 \quad \sigma_{R S}\left(z_{1}\right)=\frac{6 \sigma_{S}}{H^{2}} z_{1}^{2}-\frac{\sigma_{S}}{2}=0 \\
& z_{1}=\frac{1}{2 \sqrt{3}} H=0.288675 H
\end{aligned}
$$

The depth of the compression zone, $h_{c}=\frac{H}{2}-z_{1}=0.211 H$

\subsection{Determination of the full residual depth profile using the model: Examples}

Application of the parabolic residual stress depth profile formula derived above (i.e. Eq. (5)) for annealed and thermally-strengthened construction-sector glass is demonstrated by considering the results for a few arbitrary chosen glass specimens. Table 1 shows the manufacturer-provided surface compressive residual stress values for the chosen $6 \mathrm{~mm}$ thick 
annealed, heat-strengthened and fully-tempered glass specimens. Figure 3 shows the full residual depth profile predictions from the proposed model for each glass specimen.

Table 1: Surface compressive residual stress in different glass specimens

\begin{tabular}{cc}
\hline Glass type & $\begin{array}{c}\text { Surface (compression) } \\
\text { residual stress (MPa) }\end{array}$ \\
\hline Annealed & 5 \\
Heat-strengthened & 30 \\
Tempered & 95 \\
\hline
\end{tabular}

(a)

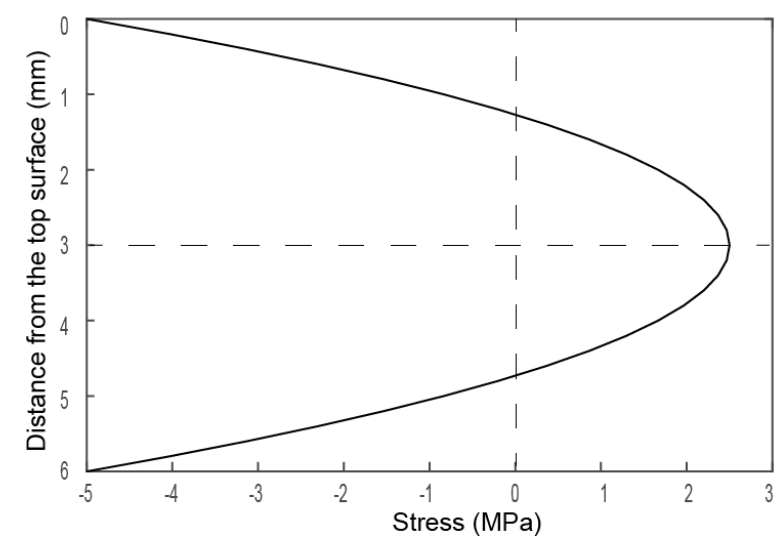

(b)

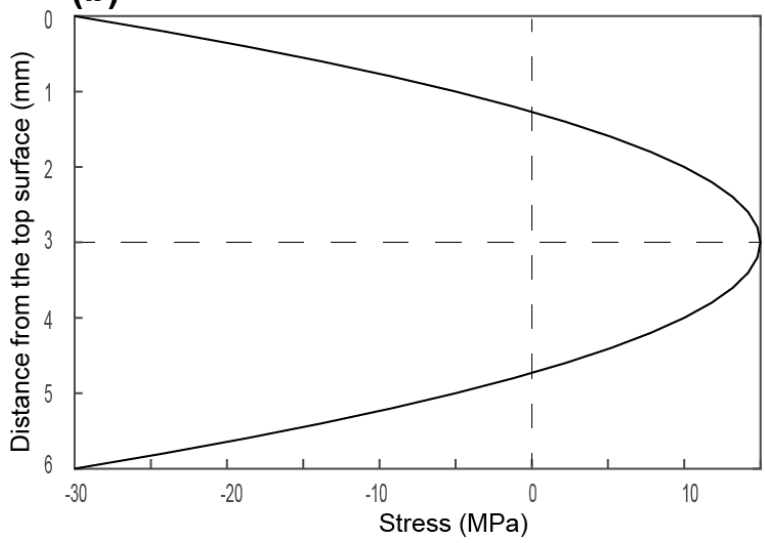

(c)

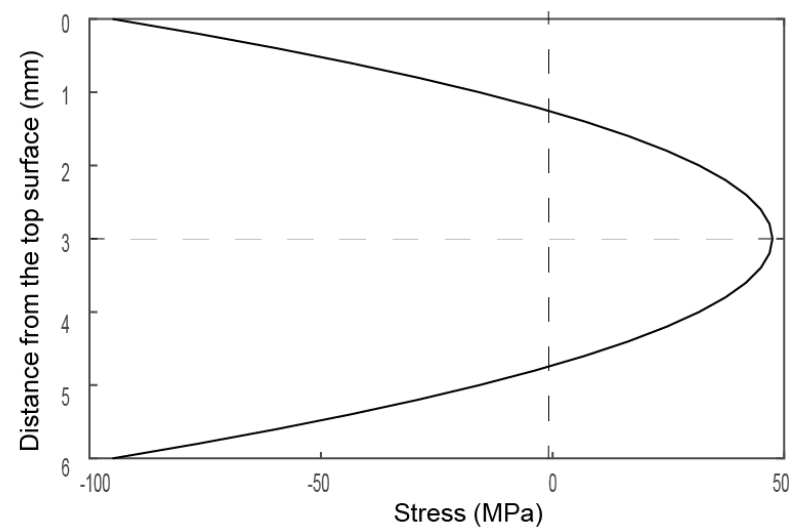

Figure 3: Residual stress depth profile predictions from the parabolic model for $6 \mathrm{~mm}$ thick: (a) annealed glass, (b) heat-strengthened glass and (c) tempered glass test specimens

\section{Comparison with reported experimental results}

Predictions from the present model (i.e. Eq. (5)) were compared against the measured residual stress depth profiles reported in the literature for several annealed, heat-strengthened and 
tempered glass specimens. For brevity, only a few selected results, covering different types of glass over a range of thicknesses, are presented in this paper. Table 2 shows the glass type, thickness and the surface residual stress of the chosen glass specimens. The quoted surface residual stress values (in Table 2), which were measured using scattered-lightpolariscopes (SCALP), match with typical stress values expected in respective glass types.

Table 2: Measured surface compressive residual stress values in glass test specimens

\begin{tabular}{lccc}
\hline \multicolumn{1}{c}{ Specimen label } & Glass type & $\begin{array}{c}\text { Glass thickness } \\
(\mathrm{mm})\end{array}$ & $\begin{array}{c}\text { Surface (compression) } \\
\text { residual stress (MPa) }\end{array}$ \\
\hline a (Balan \& Achintha [19]) & Annealed & 10 & 5.6 \\
b (Balan \& Achintha [19]) & Annealed & 6 & 6.5 \\
c (Balan \& Achintha [19]) & Tempered & 10 & 95.6 \\
d (Balan \& Achintha [19]) & Tempered & 4 & 100 \\
e (Ounapuu et al. [16]) & Tempered & 8 & 90 \\
f (Aben et al. [6]) & Heat-strengthened & 6 & 60 \\
\hline
\end{tabular}

Figure 4 shows the comparisons between the predictions from the present model against the experimentally measured residual stress depth profiles in all glass test specimens considered in Table 2. The experimentally measured residual stress data shown in Figure 4 were obtained by using reliable scattered-light-polariscopes. It is expected that the measured stress data in the surface regions of glass (typically, up to $\sim 3-4 \mathrm{~mm}$ deep from the glass surface) are usually accurate with an $\pm 5 \%$ error (e.g. [11]). In the experiments, stresses were measured from both surfaces in order to construct the through-thickness residual stress depth profile. In thick glass specimens (e.g. $10 \mathrm{~mm}$ thick glass), stress data was measured only up to a thickness where it was possible to measure the stresses reliably, and hence experimental data were not available for the middle region of $10 \mathrm{~mm}$ thick glass specimens. 
(a)

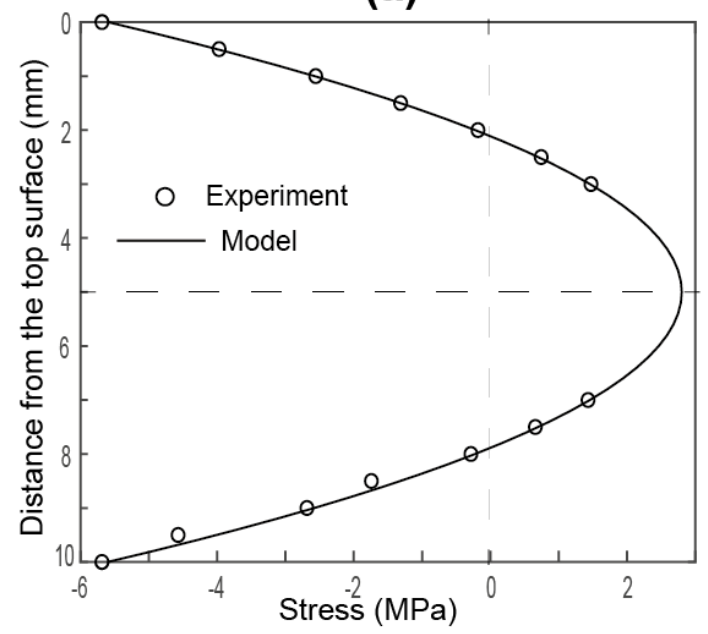

(c)

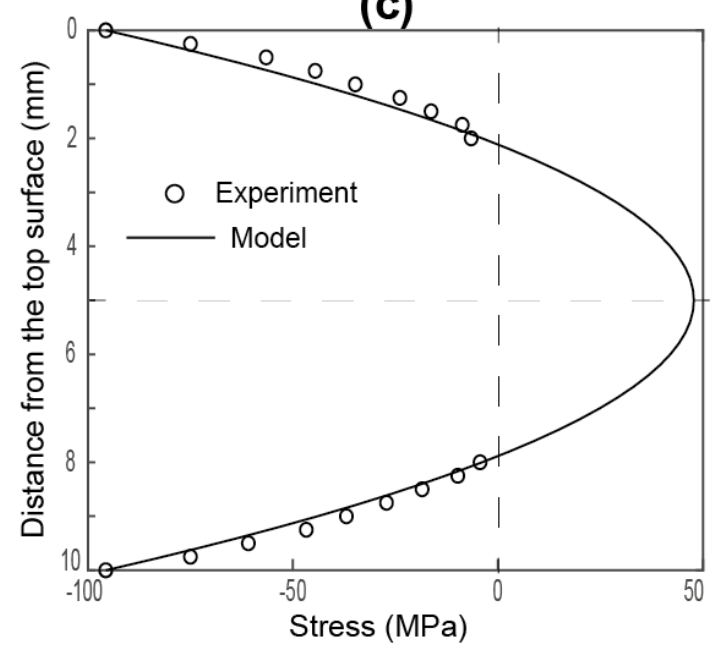

(e)

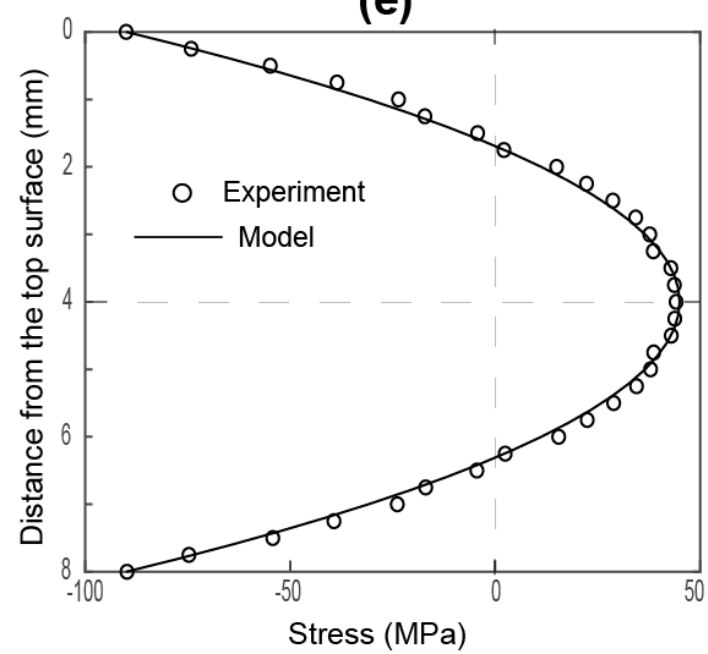

(b)

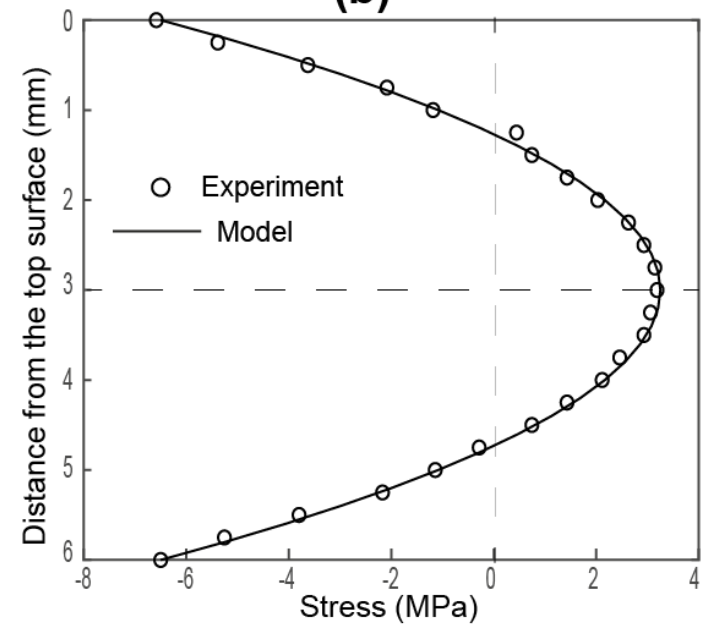

(d)

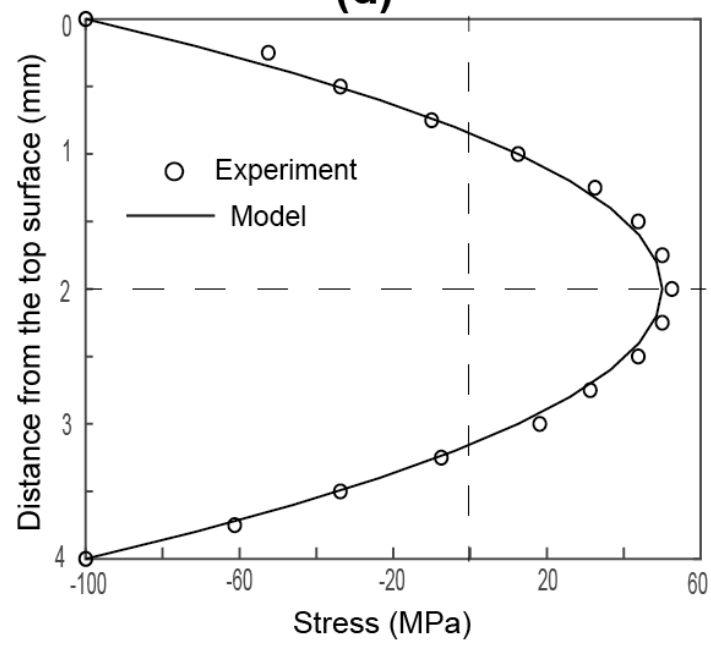

(f)

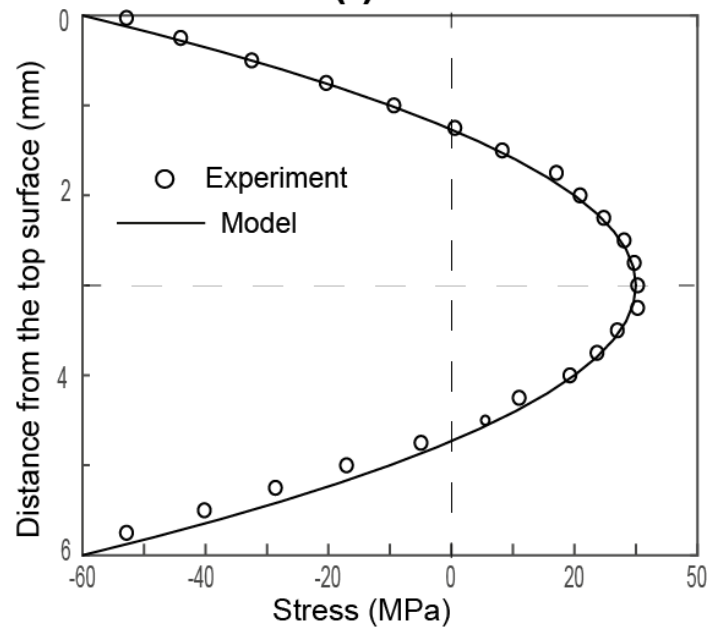

Figure 4: Experimental validation of the residual stress depth profiles: (a) $10 \mathrm{~mm}$ thick annealed, (b) $6 \mathrm{~mm}$ thick annealed, (c) $10 \mathrm{~mm}$ thick tempered, (d) $4 \mathrm{~mm}$ thick tempered, (e) $8 \mathrm{~mm}$ thick tempered and (f) $6 \mathrm{~mm}$ thick heat-strengthened glass test specimens 
The results shown in Figure 4 suggest that the parabolic model derived in the present study accurately predicts the residual stress depth profiles in all glass test specimens. Table 3 shows the comparisons between the model predicted $\left(\sigma_{\text {m_model }}\right)$ and the experimentallymeasured $\left(\sigma_{m_{-} \text {exp }}\right)$ peak tensile stress (i.e. stress at mid-thickness) for all glass specimens, except the two $10 \mathrm{~mm}$ thick glass specimens (note: mid-thickness residual stress data measurements were not available for $10 \mathrm{~mm}$ thick glass specimens, since the SCALP was not able to measure stresses beyond 3-4 $\mathrm{mm}$ from the surface of the specimen). The results shown in Table 3 suggest that the error between the model predictions and the experimentally measured peak tensile stress values are within the range of $-2.0 \%$ to $4.8 \%$. This error range is believed to be accurate enough for stress analysis of glass structures.

Table 3: Comparisons between the model predicted and the experimentally measured peak tensile stresses for different glass test specimens

\begin{tabular}{|c|c|c|c|}
\hline \multirow[t]{2}{*}{ Specimen label } & \multicolumn{2}{|c|}{$\sigma_{m}$ (mid-thickness tensile stress) } & \multirow{2}{*}{$\begin{array}{c}\% \text { Difference } \\
\left(\frac{\sigma_{m \_e x p}-\sigma_{m \_ \text {model }}}{\sigma_{m \_ \text {exp }}}\right) \times 100\end{array}$} \\
\hline & $\sigma_{m \_ \text {model }}(\mathrm{MPa})$ & $\sigma_{m \_\exp }(\mathrm{MPa})$ & \\
\hline b (Balan \& Achintha [19]) & 3.25 & 3.2 & -1.6 \\
\hline d (Balan \& Achintha [19]) & 50.0 & 52.5 & 4.8 \\
\hline e (Ounapuu et al. [16]) & 45.0 & 44.1 & -2.0 \\
\hline f (Aben et al. [6]) & 30.0 & 30.3 & 1.0 \\
\hline
\end{tabular}

The experimental results were also used to investigate the accuracy of the parabolic model prediction for the depth of the surface compression zone (i.e. $h_{c_{-} \text {model }}=0.211$ times the thickness of the glass test specimen). Table 4 shows the comparison between $h_{c \_ \text {model }}$ and that determined using the knowledge of measured residual stress data $\left(h_{c \_ \text {exp }}\right)$ for all glass specimens, except the $10 \mathrm{~mm}$ thick tempered glass specimen where SCALP was not able to reliably measure stresses into the tension zone. The results shown in Table 4 suggest that the compression zone depth determined using the experimental results (i.e. $h_{c_{-} \text {model }}$ ) vary between 
0.199 to 0.215 times the overall specimen thickness. The error of the compression zone depth determined using the results of the parabolic model varies within the range $-6 \%$ to $1.86 \%$.

Table 4: Comparisons between the compression zone depth determined using the results of the parabolic model and the results determined using the measured residual stress data

\begin{tabular}{lcc}
\hline \multicolumn{1}{c}{ Specimen label } & $\begin{array}{c}\text { Experimentally determined depth of } \\
\text { the compression zone as a fraction } \\
\text { of the overall specimen thickness }\end{array}$ & $\begin{array}{c}\text { \% Difference } \\
\left(\frac{h_{c_{\_} \text {exp }}-h_{c_{-} \text {model }}}{h_{c_{-} \text {exp }}}\right) \times 100\end{array}$ \\
\hline a (Balan \& Achintha [19]) & 0.209 & -0.96 \\
b (Balan \& Achintha [19]) & 0.199 & -6.00 \\
d (Balan \& Achintha [19]) & 0.215 & 1.86 \\
e (Ounapuu et al. [16]) & 0.208 & -1.44 \\
$f$ (Aben et al. [6]) & 0.206 & -2.43 \\
\hline
\end{tabular}

The results shown above suggest that the parabolic residual stress depth profile model can accurately predict the residual stress depth profiles in both annealed and thermallystrengthened construction-sector glass. The comparisons between the model predictions and the experimental results for all other test specimens investigated in the present study, which are not presented in this paper, were qualitatively similar to the results shown in Figure 4. No attempt was made in the present paper to model the residual stress distributions in the glass test specimens using existing numerical methods, since existing numerical models require the knowledge of thermal parameters and the viscous response of glass at different temperatures. It is impossible to know these parameters for the glass test specimens used in the present study, since they were purchased from commercial suppliers. In fact, reliable information for the parameters are unlikely to be available from the glass manufacturers. Indeed, these limitations emphasise the importance of the model proposed in the present paper where residual stress distributions can be determined using a readily available input data (i.e. stabilised surface residual stress). 


\section{Incorporation of the effects of residual stress in glass structural design}

Although the proposed parabolic model (Eq. (5)) can be used to accurately determine the residual stress depth profile in any given glass specimen, the model alone cannot be used to incorporate the effect of residual stresses in detailed stress analysis of glass structures. A previous research work [20] led by the author of the present paper showed that the concept of eigenstrains where the effects of the complex non-linear cooling process approximated with a linear elastic approach can be effectively used to incorporate the effects of full 3D distribution of the residual stresses in glass. Whilst this previous work [20] provides a comprehensive tool for modelling full 3D residual stress distributions and stress evolutions during the subsequent applied loads in glass structural design, the requirement of knowledge of the residual stress values at a few locations along the thickness of a given glass specimen hampers the practical applications of the method. This is because knowledge of through-thickness residual stress data is usually not available in practice where only the knowledge of the surface residual stress is readily available from the glass manufacturers. Since the parabolic residual stress depth profile model derived in the present study enables knowing the values of the residual stress values along the thickness of a given glass sheet, predictions from the present model can be used as known residual stress values at any chosen locations along the thickness. This knowledge can then be combined with the concept of eigenstrains in order to develop a method for incorporating the effects of residual stresses in stress analysis of glass structures.

\subsection{Eigenstrains-based modelling of residual stresses}

Since the residual stresses are generated as the results of thermal and mechanical changes occurred during cooling of hot glass, they can be modelled as the static elastic response of the glass when the resultant effect of all the thermal and mechanical actions are incorporated as an initial strain (i.e. eigenstrains). In this approach, eigenstrains distribution may be determined by first assuming a sensible choice of a parametric form and then by matching the predicted residual stresses when this assumed eigenstrains distribution was incorporated in a 
new FE model, with the corresponding known residual stress values at a few locations along the thickness direction of the glass sheet, in a least squares sense. Then by implementing the established eigenstrains distribution as an initial strain in a new FE model representing the given glass specimen, the effects of full $3 D$ residual stresses distribution can then be incorporated in the stress analysis.

\subsection{Eigenstrains depth profile}

Knowledge of all three principal components of the eigenstrains distribution is required in the proposed analysis. However, as shown in the previous work of Achintha \& Balan (2015) [20], it is only necessary to evaluate one principal component of the eigenstrains, since eigenstrains state in a given glass sheet can be assumed to be a homogeneous planar system. Therefore, the first step of the analysis is the choice of a suitable parametric form for the eigenstrains depth profile of one principal component of the eigenstrains distribution.

The analysis was started by assuming that the eigenstrains depth profile may be represented as a Chebyshev series of polynomials [21]. Chebyshev polynomials of the first kind $\left(T_{i}\left(z^{*}\right) ; i=\right.$ $0,1,2, .).[21]$ were used in the present work. A Chebyshev Polynomials-based method was used because of its convenience in least-squares analysis, although alternative methods are possible. The choice of the number $(N)$ of Chebyshev polynomials used to represent the eigenstrains depth profile is important, since the chosen eigenstrains depth profile should be able to represent the actual eigenstrains distribution with an acceptable accuracy. Given the parabolic form of the residual stress depth profile, a Chebyshev series with three polynomials (i.e. $N=3$ ), was used. Thus, the originally assumed eigenstrains depth profile (i.e. $\varepsilon_{\text {eig }}\left(z^{*}\right)$ ) was:

$$
\begin{aligned}
& \varepsilon_{\text {eig }}\left(z^{*}\right)=c_{0} T_{0}\left(z^{*}\right)+c_{1} T_{1}\left(z^{*}\right)+c_{2} T_{2}\left(z^{*}\right) \quad \text { where } z^{*}=\frac{z}{H / 2} \\
& T_{0}\left(z^{*}\right)=1 ; T_{1}\left(z^{*}\right)=z^{*} ; \text { and } T_{2}\left(z^{*}\right)=2 z^{* 2}-1 \text { and } c_{0}, c_{1} \text { and } c_{2} \text { are coefficients }
\end{aligned}
$$


As shown in Eq. (9), fraction depth with respective to the half-thickness of the glass specimen (i.e. $z^{*}$ ) was used in the analysis, since it is common in numerical analyses of Chebyshev polynomials to ensure that the value of the independent variable is between -1 and 1 .

\subsection{Determination of the eigenstrains depth profile}

Each Chebyshev polynomial (i.e. $\left.T_{i}\left(Z^{*}\right) ; i=0,1,2\right)$ of the assumed eigenstrains depth profile (i.e. Eq. (9)) was incorporated in turn as initial strains in separate FE models of the given glass specimen. The residual stress depth profile $\left(\sigma_{R S_{-} i}\left(Z^{*}\right)\right)$ corresponds to each Chebyshev polynomial was then determined. The resultant residual stress distribution (i.e. $\sigma_{R S \_ \text {mode }}\left(\mathrm{Z}^{*}\right)$ ) caused by the originally assumed full eigenstrains depth profile (i.e. $\varepsilon_{e i g}\left(z^{*}\right)$ ) was then determined as the sum of that caused by each polynomial $T_{i}\left(z^{*}\right)$ multiplied by the coefficients $c_{i}(i=0,1,2)$. The unknown coefficients $c_{i}$ were then determined by matching $\sigma_{R S_{-} \text {model }}\left(z^{*}\right)$ with the known residual stress values. Residual stress values at three locations along the glass thickness (mid-thickness $(z=0)$, surface $(z=H / 2)$ and at quarter location $(z=H / 4))$, which were determined using the parabolic residual depth profile (i.e. Eq. (5)), were used as the known residual stress data in the least-squares analysis. The step-by-step procedure of the inverse eigenstrains analysis used in the present study is shown in Figure 5. Details of a comprehensive least squares analysis of an inverse eigenstrains analysis can be found in elsewhere (e.g. [22]) and is not repeated here.

\subsection{Results: Eigenstrains depth profile}

Eigenstrains analyses were carried out for all glass specimens those considered for the validation of the residual stress depth profiles in Section 4. However, for brevity, the results for three glass specimens, $10 \mathrm{~mm}$ thick annealed and tempered and $6 \mathrm{~mm}$ thick heatstrengthened glass, are presented in this paper. Table 5 shows the coefficients $c_{i}$ determined from the inverse eigenstrain analysis of each glass specimen. 
Assumed eigenstrains distribution

(coefficeints $\mathrm{c}_{i}(i=0,1,2$,$) are unknown)$

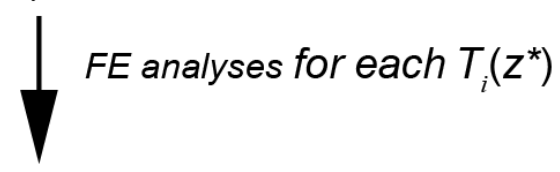

Resiual stress for each $T_{i}\left(z^{*}\right)$

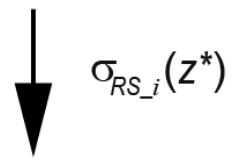

Resultant residual stress distribution $\left(\sigma_{\text {rs.moded }}\left(z^{*}\right)\right)$

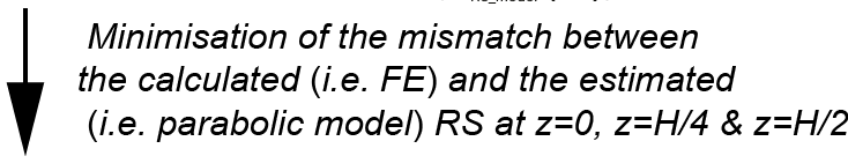

Coefficients of the Chebyshev series $\left(c_{i}\right)$

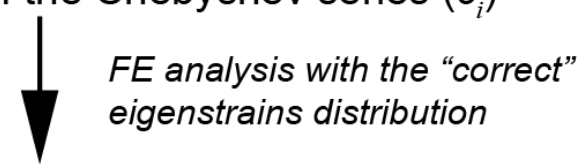

Incorporation of the effects of RS in stress analysis

Figure 5: Step-by-step procedure of the eigenstrains analysis

Table 5: Coefficients of the Chebyshev series

\begin{tabular}{lccc}
\hline \multicolumn{1}{c}{ Glass specimen } & \multicolumn{3}{c}{ Coefficients $\left(\mathrm{c}_{i}\right)$} \\
& $c_{0}$ & $c_{1}$ & $c_{2}$ \\
\hline $10 \mathrm{~mm}$ thick, annealed glass & 0 & $-6.944 \times 10^{-6}$ & $5.222 \times 10^{-5}$ \\
$10 \mathrm{~mm}$ thick, tempered glass & 0 & $-1.185 \times 10^{-4}$ & $8.915 \times 10^{-4}$ \\
$6 \mathrm{~mm}$ thick, heat-strengthened glass & 0 & $-9.390 \times 10^{-5}$ & $5.746 \times 10^{-4}$ \\
\hline
\end{tabular}

By substituting the coefficients shown in Table 1 in the Chebyshev series (i.e. Eq. (9)), an accurate estimate for the eigenstrains depth profile in each glass specimen was established. Figure 6 shows the determined eigenstrains depth profiles for all three glass specimens. As expected, the results suggest that the calculated eigenstrains depth profiles are symmetric and parabolic relative to the median plane of the glass specimen. The results also suggest that the magnitude of the eigenstrains is higher in tempered glass compared to that in heat- 
strengthened and annealed glass. Similarly, the magnitude of the eigenstrains in heatstrengthened glass is higher compared to that in annealed glass.

(a)

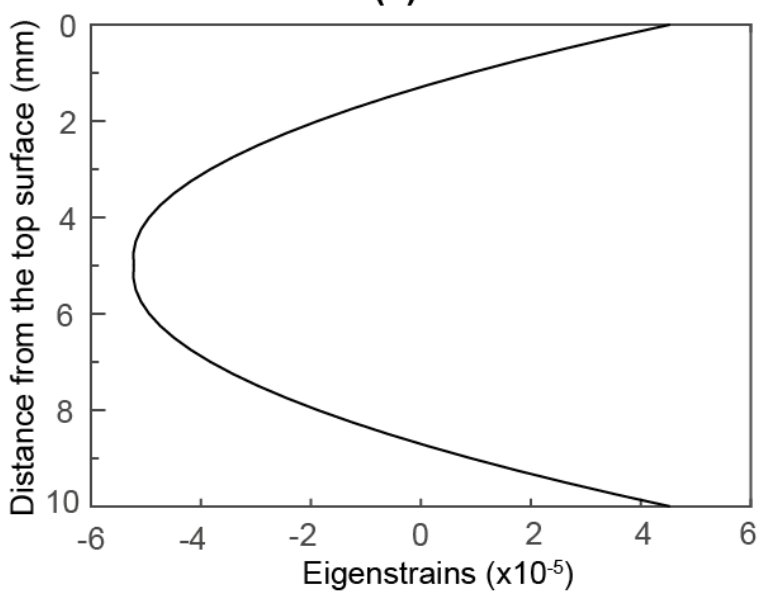

(b)

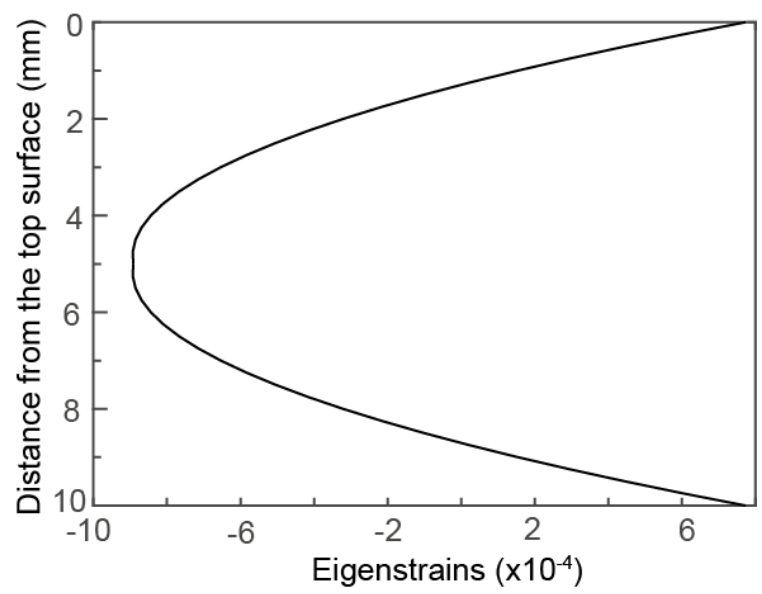

(c)

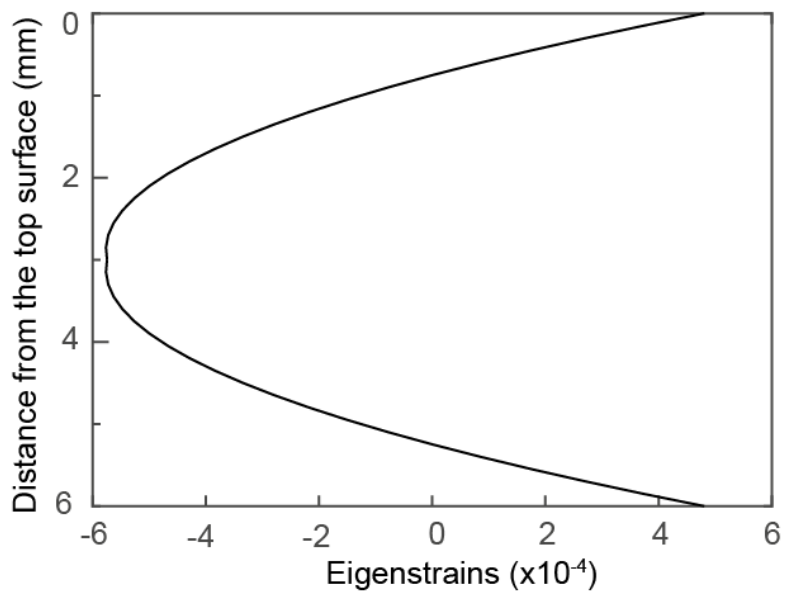

Figure 6: Eigenstrains depth profile in: (a) $10 \mathrm{~mm}$ thick annealed, (b) $10 \mathrm{~mm}$ tempered and (c) $6 \mathrm{~mm}$ heat-strengthened glass test specimens

\subsection{Results: Residual stresses}

As described in Section 5.1, the full 3D residual stress distribution in the glass specimens were determined by implementing the respective calculated eigenstrains distribution (i.e. eigenstrains depth profile shown in Figure 6) as an initial strain distribution in a FE model representing the respective glass specimen. Abaqus/CAE (2019) [23] was used for the FE analysis carried out in the present study. In the present analysis, $150 \mathrm{~mm} \times 150 \mathrm{~mm}$ glass specimens were assumed. The symmetry of the specimen in $x, y$ and $z$ directions means only one-eighth of a specimen was modelled in the FE analysis. Glass was modelled as a linear 
elastic material with Young's modulus $70 \mathrm{GPa}$ and Poisson's ratio 0.22, values often used in glass engineering literature [2]. 8-node, linear solid elements of $1 \mathrm{~mm} \times 1 \mathrm{~mm} \times 0.2 \mathrm{~mm}(x, y$ and $z$ directions, respectively) size were used to model glass. Appropriateness of the size and the type of the elements used in the FE analysis were established through a thorough sensitivity analysis. As stated previously, the knowledge of symmetry was used as boundary conditions of the one-eighth model of the actual glass test specimen. The effects of eigenstrains were conveniently modelled by specifying anisotropic thermal expansion coefficients that varied with position, together with a uniform (unit) temperature rise. This method of incorporating eigenstrains in elastic FE models has been successfully used previously (e.g. for modelling residual stresses generated in metallic structural components due to laser shock peening [24]).

The objective of the present paper was to show the applicability of the proposed model for incorporating the effects of residual stresses, and hence the use of linear-elastic material model for glass is justifiable. In commercially available FE software, it is possible to incorporate the additional loading states (e.g. live loads on a given glass structure) by simply defining a new "step" where different materials models, element types, loads, boundary conditions, etc. can be added. Therefore, fracture analysis of real-life glass structures may be carried out using appropriate element and material models together with the actual loading steps of the analysis.

Figure 7 shows the distribution of one principal stress component $\left(\sigma_{x}\right)$ of the residual stress in $10 \mathrm{~mm}$ thick annealed, $10 \mathrm{~mm}$ thick tempered and $6 \mathrm{~mm}$ thick heat-strengthened glass specimens. As expected, the results suggest that the spatial distribution of the residual stress in $x-y$ plane is largely uniform, apart from in the vicinities of the edges of the glass specimen. The results also show that in both annealed and thermally-strengthened glass, compression residual stresses exist in the surface regions, and the residual stresses become tensile in the mid-thickness regions of glass. 


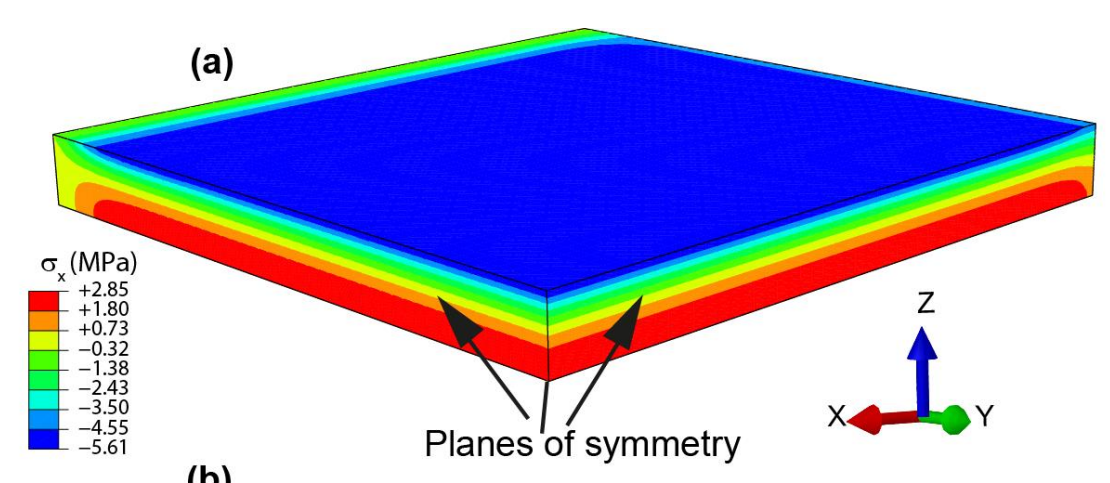

(b)
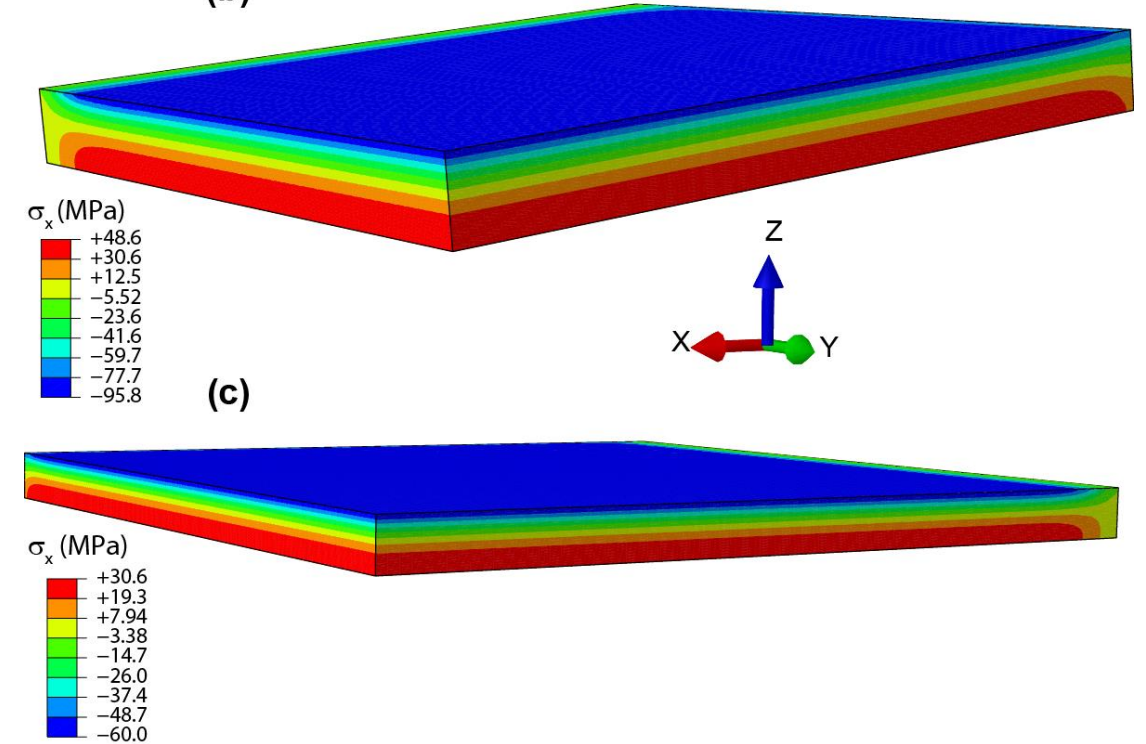

Figure 7: Full 3D residual stress distribution in: (a) $10 \mathrm{~mm}$ thick annealed glass, (b) $10 \mathrm{~mm}$ thick tempered and (c) $6 \mathrm{~mm}$ thick heat-strengthened glass test specimens

Figure 8 shows the comparisons between the residual stress depth profile predicted by the parabolic model (Eq. (5)) and that extracted from the eigenstrains-based 3D FE models (i.e. from Figure 7). As expected, the results show that the results extracted from the FE models are almost identical to the respective results determined from the parabolic residual stress depth profile formula. Thus, the results suggest that by combining the eigenstrains concept with the parabolic residual stress depth profile model, it is possible to develop a technique that can be used to incorporate the effects of the residual stresses. The eigenstrains-based FE solution for a given glass specimen satisfies equilibrium, compatibility, material behaviour and boundary conditions of the full 3D glass specimen. Therefore, the comparisons shown in Figure 8 is beyond a simple least squares fit to the residual stress data obtained from the 
parabolic model. The validated eigenstrains based analysis can later be used for incorporating the effects of residual stresses in stress analysis of glass structures.

(a)

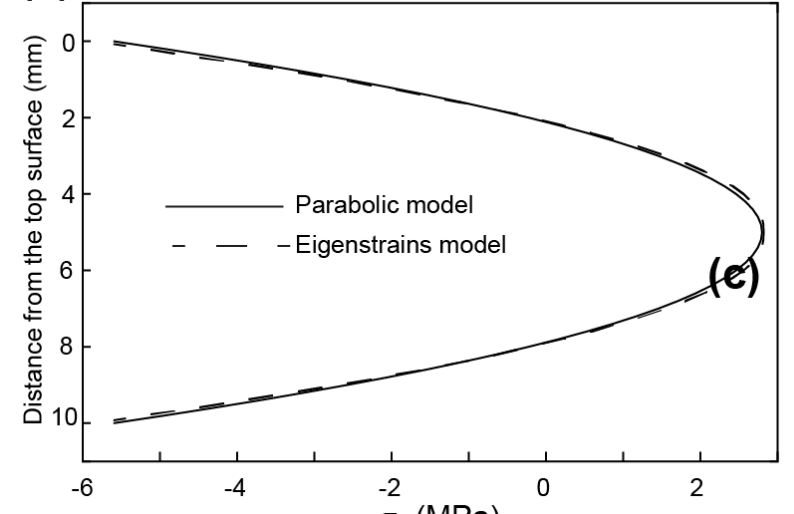

(b)

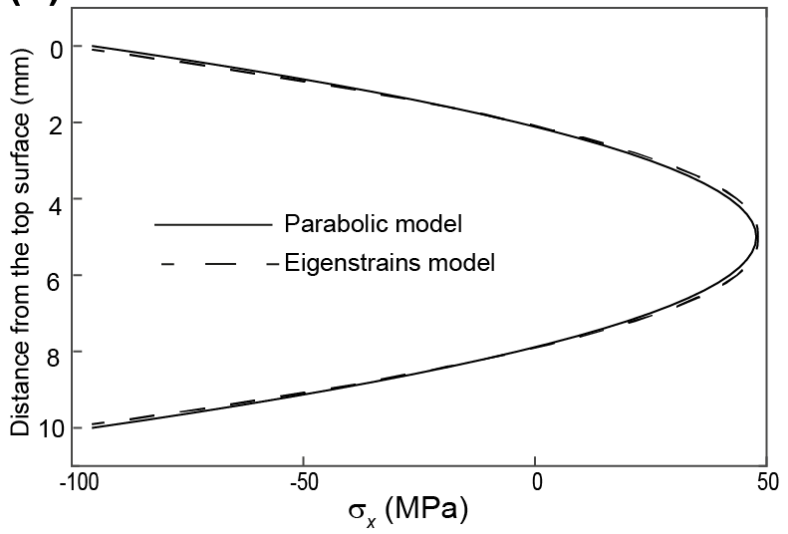

(c)

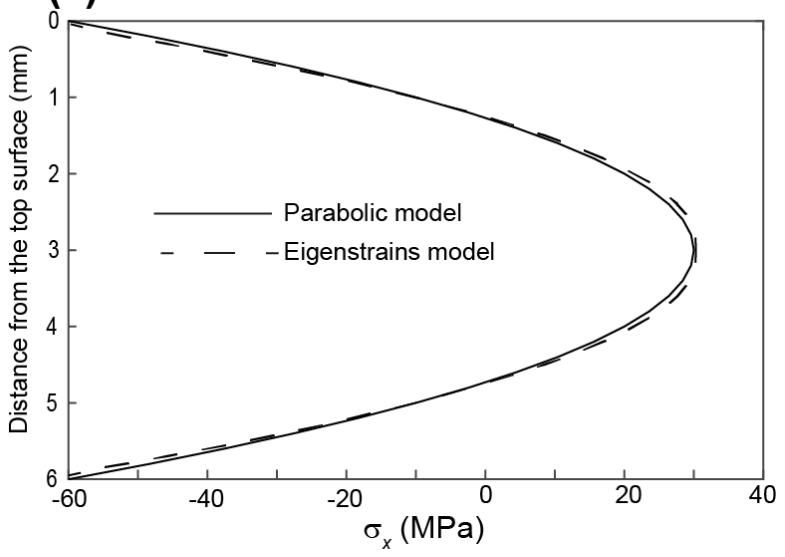

Figure 8: Comparisons between the residual stress depth profile predictions from the parabolic model and the eigenstrains analysis: (a) $10 \mathrm{~mm}$ thick annealed, (b) $10 \mathrm{~mm}$ thick tempered and (c) $6 \mathrm{~mm}$ thick heat-strengthened glass

\section{Sensitivity analysis}

The results presented above show that the effects of the residual stresses in glass can be accurately modelled using the knowledge of the surface residual stress and the parabolic model developed in the present study. Scattered-light-polariscopes (SCALP) are usually used to experimentally measure the surface stresses in construction-sector glass. Despite the reasonably good accuracy of the modern polariscopes, manufactures of SCALPs usually expect $\pm 5 \%$ error in the measured stresses (e.g. [11]). 


\subsection{Effects of the error in the used surface stress on the residual stress depth profile}

A sensitivity analysis was carried out in order to investigate the effects due to possible $\pm 10 \%$ inaccuracy in the surface residual stress value used in the analysis. $\pm 10 \%$ error/uncertainty margin was established as twice that of the likely error associated with SCALP measurement (i.e. $\pm 5 \%$ error). This limit was chosen as a means of taking into the errors in SCALP measurements as well as other possible sources of uncertainties such as minor variations in the residual stress in $x-y$ plane. As a starting point, $\pm 10 \%$ error/uncertainty margin was taught to be a realistic, conservative analysis for the results presented in this paper.

Figure 9 shows the comparisons between the experimental results and the parabolic model(i.e. Eq. (5)) predictions for residual stress depth profiles in $10 \mathrm{~mm}$ thick annealed, $10 \mathrm{~mm}$ thick tempered and $6 \mathrm{~mm}$ thick heat-strengthened glass test specimens based on the analysis with different surface stress values. The solid line in Figure 9 shows the predictions based on the actually measured surface residual stress $\left(\sigma_{s}\right)$, and the two broken lines show the predictions with the assumed surface stress values of: (1) $10 \%$ higher than $\sigma_{s}\left(\sigma_{s}^{+}\right.$in Figure 9$)$ and (2) $10 \%$ lower than $\sigma_{s}\left(\sigma_{s}^{-}\right.$in Figure 9$)$, respectively. The results suggest that effects due to the change in the surface residual stress within the chosen range is not significant and the predictions still agree well with the experimental results. Comparisons for all other glass specimens investigated in the present study, which are not shown in this paper, are qualitatively similar to those shown in Figure 9. Therefore, the results suggest that the parabolic residual stress model can accurately estimate the residual stress depth profiles in construction-sector glass products even after possible inaccuracy in the surface stress was considered in the analysis.

\subsection{Effects of the error in the used surface stress value on eigenstrains depth profiles}

The influence of the possible error/uncertainty in the surface residual stress on the predictions for the eigenstrains depth profiles was investigated using the inverse eigenstrain analysis 
described in Section 5. The knowledge of residual stress predictions from the parabolic rmodel with surface stress $10 \%$ higher and $10 \%$ lower than the actually measured stress value was used in this analysis. Similar to the previous analysis (Section 5), relevant parabolic model predictions for mid-thickness (i.e. $z=0$ ), surface $(z=H / 2)$ and at the quarter location (i.e. $z=$ $H / 4)$ were used in this inverse eigenstrain analysis.

(a)

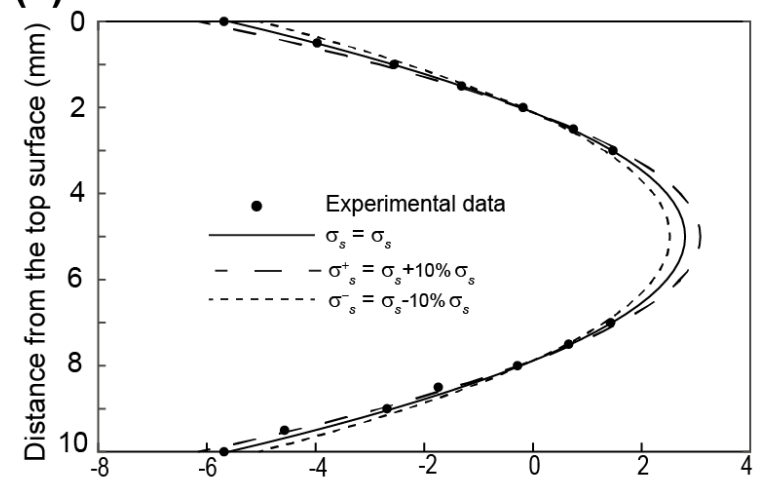

(b)

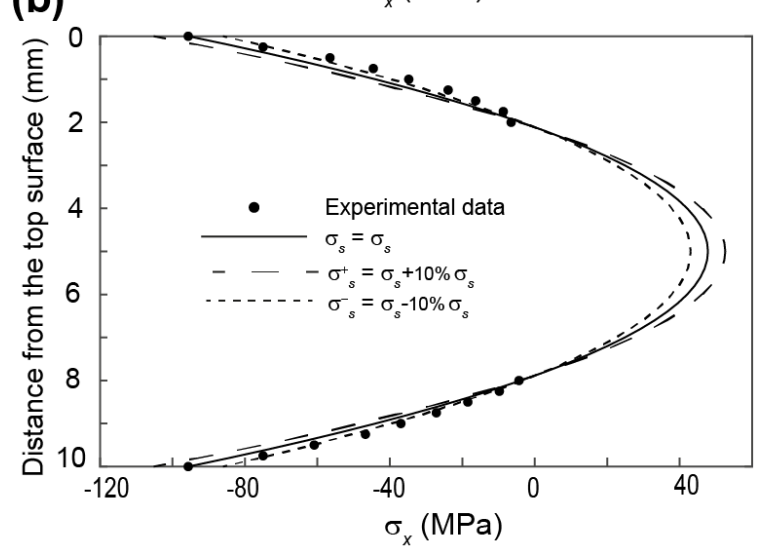

(c)

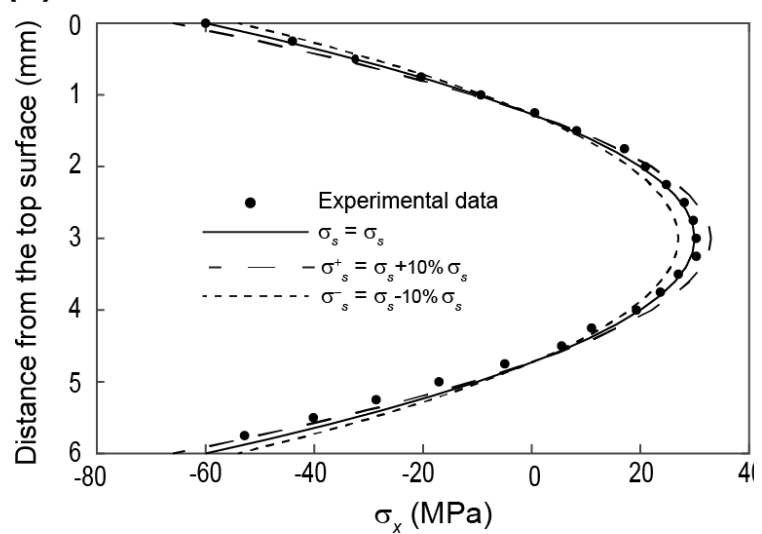

Figure 9: Comparisons between the predicted residual stress depth profile based on different surface stress values and the measured residual stresses: (a) $10 \mathrm{~mm}$ thick annealed, (b) $10 \mathrm{~mm}$ thick tempered and (c) $6 \mathrm{~mm}$ thick heat-strengthened glass

Table 6 shows the calculated $c_{1}$ and $c_{2}$ coefficients for the best-fit second order Chebyshev series for eigenstrains distribution based on the analysis with surface stress values $\sigma_{s}, \sigma_{s}^{+}$and $\sigma_{s}^{-}$, respectively (Note: coefficient $c_{0}=0$ in all cases). Results shown in Table 6 suggest that the coefficients for $\pm 10 \%$ cases may alternatively be determined by using the coefficients 1.10 and 0.90 , respectively. Figure 10 shows the comparisons between the eigenstrains depth profiles determined for all three glass test specimens based on the inverse eigenstrains analysis with three surface stress values, respectively. 
Table 6: Coefficients of the Chebyshev series based on different surface residual stress values

\begin{tabular}{ccccc}
\hline Glass & & \multicolumn{3}{c}{ Surface residual stress } \\
specimen & $c_{i}$ & $\sigma_{s}$ & $\sigma_{s}^{+}$ & $\sigma_{s}^{-}$ \\
\hline $10 \mathrm{~mm}$ thick, & $c_{1}$ & $-6.944 \times 10^{-6}$ & $-7.639 \times 10^{-6}$ & $-6.250 \times 10^{-6}$ \\
annealed glass & $c_{2}$ & $5.222 \times 10^{-5}$ & $5.744 \times 10^{-5}$ & $4.700 \times 10^{-5}$ \\
$10 \mathrm{~mm}$ thick, & $c_{1}$ & $-1.185 \times 10^{-4}$ & $-1.304 \times 10^{-4}$ & $-1.067 \times 10^{-4}$ \\
tempered glass & $c_{2}$ & $8.915 \times 10^{-4}$ & $9.807 \times 10^{-4}$ & $8.024 \times 10^{-4}$ \\
6 mm thick, heat- & $c_{1}$ & $-9.390 \times 10^{-5}$ & $-1.033 \times 10^{-4}$ & $-8.451 \times 10^{-5}$ \\
strengthened glass & $c_{2}$ & $5.746 \times 10^{-4}$ & $6.320 \times 10^{-4}$ & $5.171 \times 10^{-4}$ \\
\hline
\end{tabular}

(a)

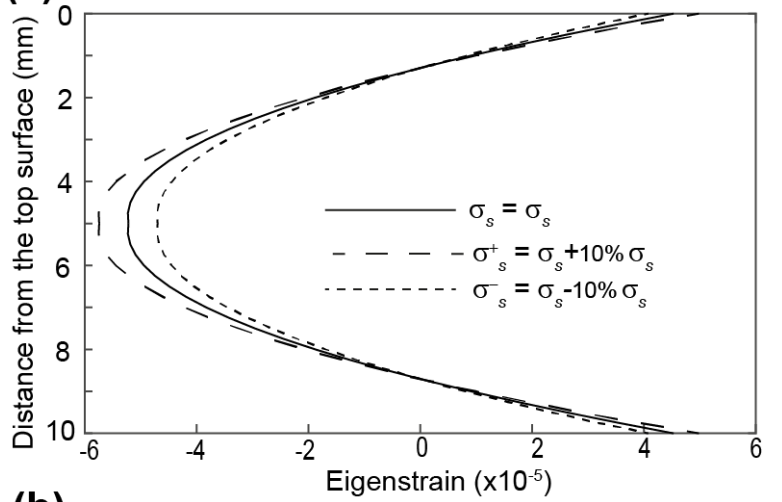

(b)

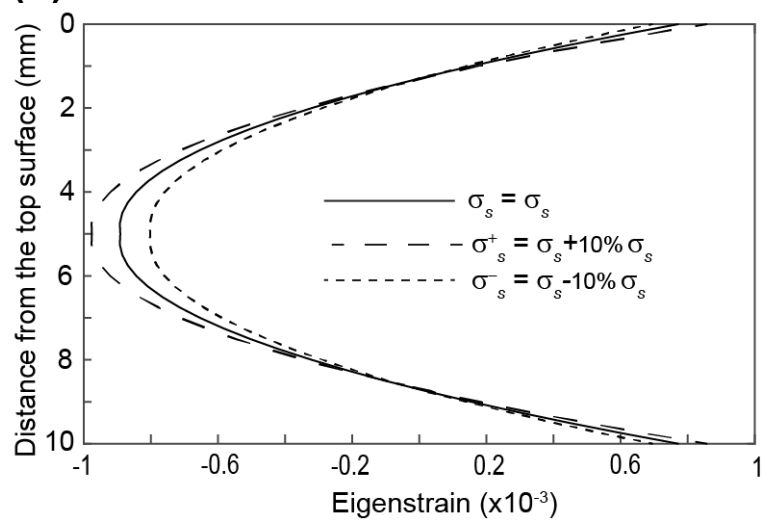

(c)

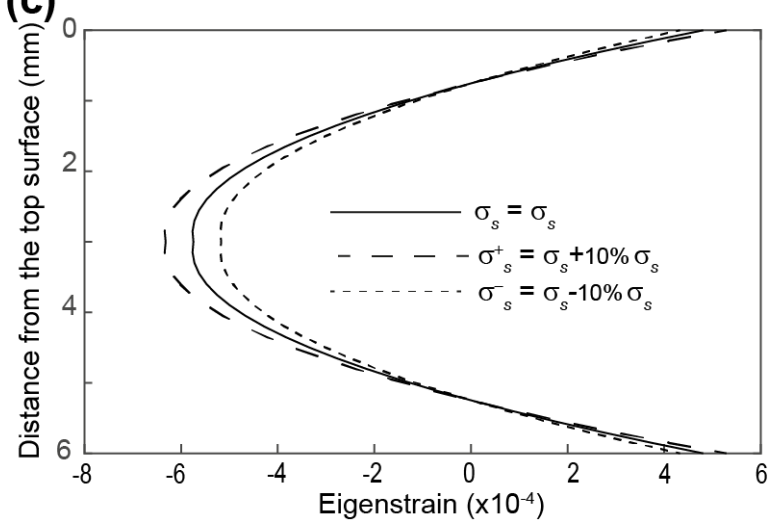

Figure 10: Eigenstrains depth profiles based on different surface stress values: (a) $10 \mathrm{~mm}$ thick annealed, (b) $10 \mathrm{~mm}$ thick tempered and (c) $6 \mathrm{~mm}$ thick heat-strengthened glass

The effect of different eigenstrains depth profiles (i.e. Figure 9) on the residual stress distribution was investigated by modelling the respective full 3D residual stress distribution by incorporating corresponding eigenstrain distributions as initial strain distributions in FE models using the method described in Section 5.4. Figure 11 shows the comparisons between the 
experimentally measured and the residual stress depth profiles extracted from the FE models with three different eigenstrains distributions in each glass specimen. The results show that for each glass test specimen, the experimentally measured results still match with the FE predictions based on all three eigenstrains depth profiles. This suggests the effect of the change in the surface residual stress value within the chosen range did not significantly influence the predictions from the eigenstrains analysis-based FE models. Thus, the modelling technique developed in the present study can be used to accurately model the residual stresses in construction-sector glass even after the effects of inaccuracy/uncertainty in the only input data - i.e. surface residual stress - was considered in the analysis.

(a)

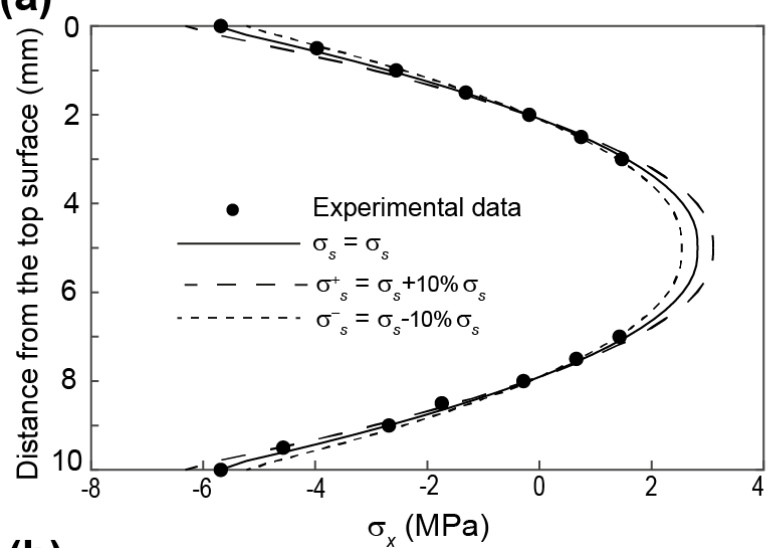

(b)

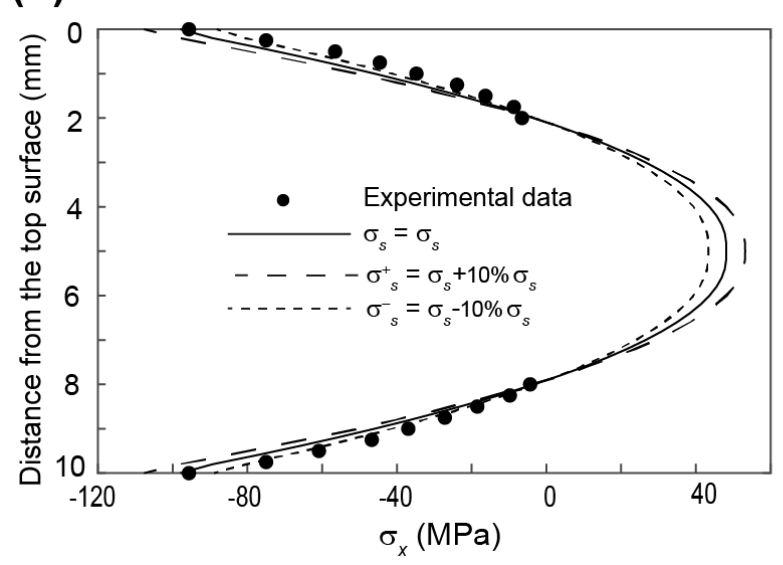

(c)

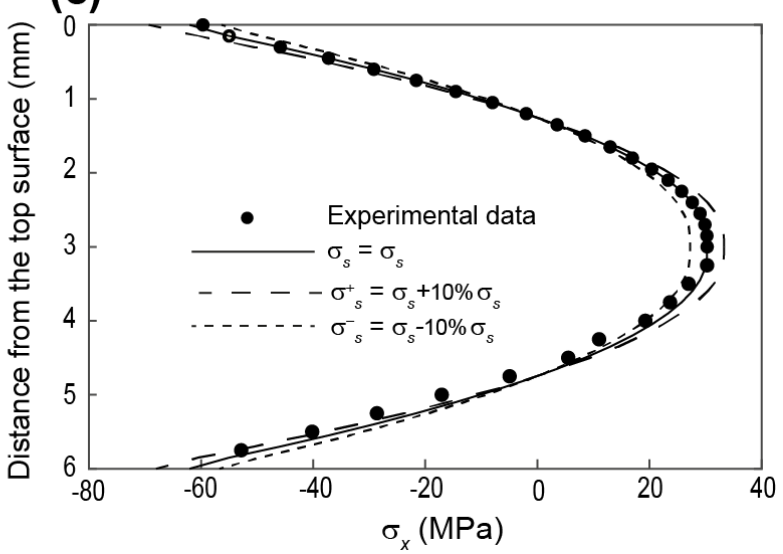

Figure 11: Comparisons between the eigenstrains-based FE model predicted residual stress depth profiles and the measured residual stresses: (a) $10 \mathrm{~mm}$ thick annealed, (b) 10 $\mathrm{mm}$ thick tempered and (c) $6 \mathrm{~mm}$ thick heat-strengthened glass 


\section{Conclusions}

- A simple parabolic model for residual stress depth profiles in construction-sector glass was developed.

- The model requires only the knowledge of the surface residual stress, which is usually available from the glass manufacturer, as input data. Thus, the method obviates the need of sophisticated scattered-light-polariscopes, which are usually not available among design engineers, in order to characterise the residual stresses in glass.

- The predictions from the proposed parabolic residual stress depth profile model were validated against the measured (using SCALP) residual stress depth profiles reported in the literature for both annealed and thermally-strengthened glass test specimens.

- Residual stresses in the vicinities of edges and holes can be different to that in the middle regions of glass panels given complex cooling mechanism(s) of hot glass around edges and holes compared to that in the middle regions. Application of the parabolic model for the analysis of residual stresses around edges and holes in glass is proposed for a future study.

- The knowledge of the proposed parabolic residual stress depth profile was extended to develop an eigenstrains-based modelling technique for modelling full 3D residual stress distributions in glass test specimens. The technique was based on first establishing eigenstrains using the knowledge of the predictions from the parabolic model.

- A sensitivity analysis on the effects of possible $\pm 10 \%$ inaccuracy/uncertainty in the surface residual stress value used in the model suggests that the modelling technique 
developed in this paper can still be used to accurately model the residual stress distributions in construction-sector glass even after the effects of inaccuracy/uncertainty in the only input value - i.e. surface residual stress - are included in the analysis.

\section{Data access statement}

All data supporting this study are openly available from the University of Southampton repository at https://doi.org/10.5258/SOTON/D1611.

\section{Appendix A.}

$$
\begin{gathered}
\sigma_{s}=a h_{1}^{2}+\sigma_{m} \quad \text { Eq. (1) } \\
a=\frac{\sigma_{s}-\sigma_{m}}{h_{1}^{2}} \text { Eq. (A.1) } \\
\int_{0}^{h 1} \sigma_{R S}(z) d z=\int_{0}^{h 1}\left(a z^{2}+\sigma_{m}\right) d z=0 \quad \text { Eq. (2) }
\end{gathered}
$$

$\left[\frac{a z^{3}}{3}+\sigma_{m} z\right]_{0}^{h_{1}}=0 \quad$ Eq. (A.2) $\quad \frac{a h_{1}^{2}}{s}+\sigma_{m}=0 \quad$ Eq. (A.3)

Substitute Eq. (A.1) in Eq. (A.3)

$\frac{\sigma_{s}-\sigma_{m}}{h_{1}^{2}} h_{1}^{2}+\sigma_{m}=0 \quad \sigma_{m}=\frac{\sigma_{s}}{2}$ Eq. (A.4)

Substitute Eq. (A.4) in Eq. (A.1) $a=\frac{\sigma_{S}+\frac{\sigma_{S}}{2}}{(H / 2)^{2}} \quad a=\frac{6 \sigma_{S}}{H^{2}}$

\section{References}


[1] Achintha, M. (2016). Sustainability of glass in construction. In J. Khatib (Ed.), Sustainability of Construction Materials, 2nd Edition (pp. 79-104). Cambridge, GB: Woodhead Publishing. DOI: 10.1016/B978-0-08-100370-1.00005-6

[2] Haldimann, M., Luible, A. Overend, M. (2008). Structural use of glass. Zurich: International Association for Bridge and Structural Engineering, 2008, 215 pp.

[3] Narayanaswamy, O.S. (1971). A model of structural relaxation in glass. Journal of the American Ceramic Society; 54: 491-498. doi.org/10.1111/j.1151-2916.1971.tb12186.x

[4] Narayanaswamy, O.S. (1978). Stress and structural relaxation in tempering glass. Journal of the American Ceramic Society; 61: 146-152. doi.org/10.1111/j.1151-2916.1978.tb09259.x

[5] The Institution of Structural Engineers (IStructE). (2014) Structural use of glass in buildings. 2nd ed. London: The Institution of Structural Engineers. London, UK.

[6] Aben, H., Anton, J., Errapart, A., Hodemann, S., Kikas, J., Klaassen, H., Lamp, M. (2010). On non-destructive residual stress measurement in glass panels. Estonian Journal of Engineering, 16(2) 150-156. DOI: 10.3176/eng.2010.2.04.

[7] Withers, P.J., Turskia, M., Edwards, L., Bouchard, J.,.Buttle, D.J. (2008). Recent advances in residual stress measurement. International Journal of Pressure Vessels and Piping, 85(3):118-127. doi.org/10.1016/j.jpvp.2007.10.007

[8] Aben, H., Anton, J., Errapart, A. (2008). Modern photoelasticity for residual stress measurement in glass. Strain, 44:40-48. doi.org/10.1111/j.1475-1305.2008.00422.x

[9] Zaccaria, M., Overend, M. (2014). The mechanical performances of bi-treated glass. In: Proceedings of the conference of challenging glass 4 \& COST action TU0905 final, Lausanne, 6-7 February 2014. London, UK: Taylor \& Francis Group.

[10] Aben, H., Lochengnies, D., Chen, Y., Anton, J., Paemurru, M., Ois, M. (2015) "A new approach to edge stress measurement in tempered glass panels" Experimental Mechanics, 55:483-486. DOI 10.1007/s11340-014-9950-7

[11] SCALP instruction manual, ver. 5.0. (2015). Tallinn: GlasStress Ltd.

[12] Nielsen, J.H., Olesen, J.F., Poulsen, P.N, Stang, H. (2010). Finite element implementation of a glass tempering model in three dimensions. Computers and Structures 88: 963-972. doi.org/10.1016/j.compstruc.2010.05.004

[13] Pourmoghaddam, N., Schneider, J. (2018) Experimental Investigation into the fragment size of tempered glass. Glass Structures and Engineering, 3(2):167-181. doi.org/10.1007/s40940-018-0062-0

[14] Sarkisov, P.D., Smirnov, M.I., Spiridonov, Y. A., Karapetyan, A.R. (2012). Effect of residual stress in float-glass on cutting quality. Glass and Ceramics, 69(5):11-15. DOI: $10.1007 / \mathrm{s} 10717-012-9434-0$

[15] Castellini, P., Stroppa, L., Paone, N. (2012). Laser sheet scattered light method for industrial measurnment of thickness residual stress distribution in flat tempered glass". Optics and Laser Engineering, 50: 787-795. doi.org/10.1016/j.optlaseng.2011.12.008

[16] Ounapuu, E., Anton, J., Klauson, A. (2019). Modelling residual stress in glass structures. AIP Conference Proceedings 2116, 330007. doi.org/10.1063/1.5114345 
[17] Daudeville, L., Carre, H. (1998). Thermal tempering simulation of glass plates: inner and edge residual stress. Journal of Thermal Stresses 21(6); 667-689. doi.org/10.1080/01495739808956168

[18] MathBitsNotebook.com - Parabola Equations.

https://mathbitsnotebook.com/Geometry/Equations/EQParabola.html [accessed on 23/03/2020]

[19] Balan, B., Achintha, M. (2015). Assessment of stresses in float and tempered glass using eigenstrains. Experimental Mechanics, 55:1301-15. DOI: 10.1007/s11340-015-0036-y

[20] Achintha, M., Balan, B. (2015). An experimentally validated contour method/eigenstrains hybrid model to incorporate residual stresses in glass structural designs. Journal of Strain Analysis for Engineering Design, 50:614-27. DOI: 10.1177/0309324715601914

[21] Mason, J.C., Handscomb, D.C. (2003). Chebyshev polynomials, Chapman \& Hall/CRC, Boca Raton, FL, 2003.

[22] Korsunsky, A.M. (2009). Eigenstrain analysis of residual strains and stresses. Journal of Strain Analysis for Engineering Design, 44: 29-43. DOI: 10.1243/03093247JSA423

[23] ABAQUS/CAE (Standard) (2019). Simulia.

[24] Achintha, M., Nowell, D. (2011). Eigenstrain modelling of residual stresses generated by laser shock peening. Journal of Materials Processing Technology. 211(6):1091-1101. DOI: 10.1016/j.jmatprotec.2011.01.011. 